This is an electronic reprint of the original article. This reprint may differ from the original in pagination and typographic detail.

Author(s): Wahlström, Jarl; Seilonen, Minna-Leena

Title: Displaying agency problems at the outset of psychotherapy

Year: $\quad 2016$

Version:

Please cite the original version:

Wahlström, J., \& Seilonen, M.-L. (2016). Displaying agency problems at the outset of psychotherapy. European Journal of Psychotherapy \& Counselling, 18(4), 333-348. https://doi.org/10.1080/13642537.2016.1260616

All material supplied via JYX is protected by copyright and other intellectual property rights, and duplication or sale of all or part of any of the repository collections is not permitted, except that material may be duplicated by you for your research use or educational purposes in electronic or print form. You must obtain permission for any other use. Electronic or print copies may not be offered, whether for sale or otherwise to anyone who is not an authorised user. 
Jarl Wahlström ${ }^{1}$ and Minna-Leena Seilonen ${ }^{2}$

\section{Displaying Agency Problems at the Outset of Psychotherapy}

Final draft ${ }^{3}$

${ }^{1}$ Department of Psychology, University of Jyväskylä, Finland

${ }^{2}$ Private practice, Tampere, Finland

${ }^{3}$ This aticle has been published as:

Wahlström, J., \& Seilonen, M.-L. (2016). Displaying agency problems at the outset of psychotherapy. European Journal of Psychotherapy \& Counselling, 18 (4), 333-348. doi:10.1080/13642537.2016.1260616 


\begin{abstract}
In order to present him- or herself at the outset of psychotherapy as a credible client, the person needs to, on one hand, formulate a sense of lost agency in accounts of his/her life situation, and on the other, to present him- or herself as willing and able to take part in conversational selfexploration. In this study we looked in detail at how one person, seeking psychotherapy, constructed accounts that served this double function. We sought to develop the usefulness of the concept of agency as an integrative theoretical construct of core processes in therapy and introduced a model of five aspects of agentic vs. non-agentic presentation, developed and applied in an earlier study on clients in semi-mandatory counselling. The results show how those aspects - relationality, causal attribution, intentionality, historicity, and reflexivity - were present in, or lacking from, accounts given by this one client entering voluntary psychotherapy. We conclude that qualitative process research could benefit from considering loss of agency as one crucial object of psychotherapy and the ongoing discursive formulations and re-formulations of the client's more or less agentic positions as central to the process of therapy.
\end{abstract}

Key words: agency, problem accounts, therapy discourse, positions, client 


\section{Introduction}

Agency as a construct has different uses in psychotherapy research (Mackrill, 2009). The client's experience of loss of agency in his/her life has been conceptualized as a prime reason for seeking help from conversational therapy (Wahlström, 2006) and the participation of the client as an active agent is seen as prerequisite for the change process (Levitt, Pomerville, \& Surace, 2016).

In this study, taking a constructionist and discursive stance, we look upon the process of therapy as an ongoing opening of new discursive formulations of the client's positions in regards to his/her problems (Avdi, 2012). Some of these positionings will be more, and some less agentic. From an institutional point of view, in order to act as an active participant in such a process, the person seeking treatment needs to present him- or herself as a credible client. This involves two interdependent discursive tasks: 1) to formulate a sense of lost agency in accounts of his/her life situation, and 2) to display him- or herself as willing and able to take part in conversational selfexploration. "Credibility" here refers to the institutional role and position of a client, i.e. adopting a social discourse to which both the client and the therapist subscribe.

In the present single case study we look upon how one prospective client presented her problems in her first psychotherapy session. Our interest is in how the client's problem formulations display and construct for her various agentic or non-agentic positions. With a background both in psychotherapy practice and in qualitative process research, we seek to develop the usefulness of the concept of agency as a theoretical construct which could further an integrative understanding of some core processes in therapy. To do this we see the need to acknowledge the complexity of the concept and the several aspects to it.

Agency refers to "the power to do" or "the force that causes effects" (Pope, 1998, pp. 242243), and the notion of an agent to someone capable of doing things and making things happen, implying some activity and independence. An essential feature of agency is being able to intentionally cause change in the world and to differentiate between actions and events caused by 
oneself and conditions attributable to external causes (Kögler, 2010; 2012). Thus two salient aspects of agency are intentionality and causal attribution.

An agent is seen as capable of making intentional and constructive choices, changing the course of his or her actions, potentially reaching self-nominated goals, and thus of genuinely creating his or her life (Avdi, 2005; Jenkins, 2001). Reaching such an agentic stance calls for some distance to the self and critical self-observing, i.e. a reflexive position in relation to one`s thinking, acting, and different aspects of the self (Dimaggio, 2011; Georgaca, 2001; Rennie, 2010). Such a reflexive posture affords also the possibility to view certain impulses or desires as problematic, unwanted or inauthentic (Kögler, 2012). Thus a salient aspect of agency is reflexivity.

From a narrative perspective, agency is engaging oneself in narrative self-constructions (Bruner, 1990). In such construction, assuming a reflective perspective affords present experiences and actions to be presented as related to past, as well as future, events, experiences, or actions, thus producing continuity in personal life stories (Georgaca, 2001). This conception outlines agency as a temporal process where the narrated past is reconstructed within the present and carried on into alternative forthcoming possibilities (Kupferberg \& Green, 2005; Ogden, 1986). Thus a salient aspect of agency is historicity.

According to Harré (1995), the notion of agency has to be related to the position of the person within a social and moral order. Such a standpoint, emphasizing intersubjectivity as a fundamental constituent of agency, has been endorsed also by Gillespie (2012), Kögler (2012), Ogden (1986), and Markova (2003). Agentic actors, while embedded in one situation, transcend this and take more general perspectives, including those of other actors. Thus a salient aspect of agency is relationality.

Loss of agency, then, can be conceptualized in terms of the person constructing him- or herself as being in the position of an object or victim of some "alien" entity, e.g. an experience, a circumstance, an illness etc., which is initiating some action, or is controlling or unduly influencing 
him or her (Avdi, Lerou, \& Seikkula, 2015; Karatza \& Avdi, 2011; Kupferberg \& Green, 2005; Ogden, 1986). Non-agentic positions have been defined as not having a place in conversations where meanings pertinent to one's life are produced (Drewery, 2005), not having access to a selfauthored autobiography (Bamberg, 2009), nor to have the option to take a reflexive, critical or evaluative standpoint in respect to the self and its actions (Avdi, 2012).

We look upon such loss of agency as being on one hand an actual state of affairs in a person's life - bringing about a genuine sense of lost agency -, and on the other hand a discursive presentation or display of oneself as being in a non-agentic position. Paraphrasing Harré's (1995, 123 ) notion that "being an agent and displaying oneself as an agent is one and the same", we argue that "being a non-agent and displaying oneself as a non-agent is one and the same". Thus problem formulations in psychotherapy, i.e. accounts of the sensation of lost mastery in some life situation(s), have a double function. Such accounts are simultaneously 'genuine' expressions of an experience and means of seeking a position in the actual situational context of the therapy session.

The aim of this study was to look in detail at how a person seeking voluntary psychotherapy constructed accounts that served the aforementioned double function of expressing the experiential loss of sense of agency and of taking the position as a potential client. When doing this, our second - and actually more definitive - aim was to introduce and try out the transferability (Lincoln \& Guba, 1985) of a model of five aspects of agentic versus non-agentic display, originally created by us in a study of disclaims of agency presented by repeated drunk driving clients entering semimandatory counselling (Seilonen \& Wahlström, 2016). In that study it was found that the model could differentiate between the cases in a meaningful way, and contribute to an understanding of the clients' ways of positioning themselves in semi-mandatory counselling, as well as of their uses of the counselling context. In the present study we ask how this model can show how the different aspects of agency constructions are present in, or lacking from, accounts given by the client entering voluntary psychotherapy. 


\section{Method}

With the aim to review varieties of agentic versus non-agentic self-presentations in psychotherapy we performed a theory-guided qualitative content analysis (Mayring, 2014) of the speech turns of one client during her first visit to a university based psychotherapy training clinic in Finland. The theoretical model that guided the analysis has been developed by us in an earlier study (Seilonen \& Wahlström, 2016).

\section{Participants and Data}

The client-participant was a female, married high school teacher, in her 30's, who had been on maternity leave for four and a half years, and returned to her work a couple of months before seeking therapy. Like all clients to the clinic she also was self-referred, but actually her father was the one who had first contacted the clinic. In her own initial telephone call and at the beginning of the first session, the client presented as her problem her social anxiety which caused her to be over conscientious in her work and fearful of her pupils' reactions. The work health service, which she had contacted a few weeks earlier, had diagnosed her as being burned out and moderately depressed. Later in the first session she talked a lot about the problems in her relationship with her husband, due partly to his drinking behaviour.

The therapist-participant was a female qualified psychologist in her early 30 's who was at the time of the treatment specializing in integrative psychotherapy at the training clinic. The input of the therapist to the conversation in this session was remarkably small. After having asked the client to tell about her situation "in her own words" she mainly used small continuers to signal her stance of empathic listening. There were a few important turns, though, in which she showed her responsiveness to the client's accounts. These had, without doubt, an important influence on the development of the client's telling but are not the object of analysis in this study. 
The primary data of the study consisted of a video-recording of the first session, and the verbatim transcript thereof. The transcript amounted to 26 pages and 779 lines. The session was conducted in Finnish, and the analysis was performed on the original Finnish transcript. Short excerpts from the transcript have been translated into English for the purpose of this article. The participants gave their informed consent to the use of the data according to a protocol reviewed by the university's Ethical Committee.

\section{Analysis}

As a first step of analysis both authors read independently the data and coded the client's turns according to the model of aspects of agency display, determining what aspect the passage in question expressed, and whether it was agentic or non-agentic. In consensus meetings the coding of the passages was reviewed. Then as a second step the displays of agency versus non-agency in the evolving problem formulations and life accounts according to each aspect were subjected to consensual qualitative content analysis.

\section{The Five Aspect Model}

The model that informed the content analysis (Seilonen \& Wahlström, 2016) argues that five interrelated aspects of agency - relationality, causal attribution, intentionality, historicity, and reflexivity - can be identified as present in, or missing from, life-accounts given by clients in counselling or therapy contexts. The presence or absence of an active formulation of the aspect contributes to rendering the presentation of the client as agentic or non-agentic.

Relationality is defined as presentations of others in relation to self, intersubjective perspective-takings, boundaries between self and others, and connections between the self and others.

Causal attributions are defined as presentations of varied phenomena and the doings of actors (self and others) as caused either externally or by the actors, including the speaker him- or herself. 
Intentions are defined as presentations of the actors' aims and purposes in varied life situations (including the presenting problems) and in the situation of giving the account (the therapy session).

Historicity is defined 1) as the temporal sequencing of events within the account into an understandable story, and 2) as the dialectics between temporal, experienced positions in the life situation accounted for and their interpretation in the present moment of telling.

Reflexivity is defined as evaluative and reflective talk in regard to the life situation or problem accounted for. When present in an account, reflexivity is usually connected to some other aspect of agency.

\section{Results}

In the course of analysis, passages relevant to each aspect of agency were identified. Reading the passages assigned to different aspects, it became evident that the client's presentation of agency or non-agency changed and evolved as her accounting of her difficulties and her different lifesituations carried on. It also became obvious that the different aspects diverged in relation to how they contained agentic versus non-agentic display. In the following we present condensed expositions of each aspect. The presentation includes short illustrative excerpts from the data. Their locations in the transcript are indicated with line-numbers.

\section{Relationality}

Within the relational field that emerged through her accounts, the client mainly displayed herself as non-agentic. There was, though, variations both in respect to topics and to how the telling progressed as the session went on. The relational field included her husband and children (mentioned for the first time in line 11), her pupils and their parents (line 42), her sisters and friends (line 82), her parents (line 107), the headmaster of her school (line 108), the physician and the psychologist from her work health services (lines 122 and 132), and some women in an Al Anon group (line 427). 
In relation to her sisters and parents she presented herself at the beginning of the session as emotionally reactive and helpless - she "bursts into tears" (line 61) when talking to them, and they are the ones who urge her to seek help. In that respect she pictured herself as utterly non-agentic: "then again this my other sister said that now one has to seek some help" (line 102). Later in the session she says that her parents described her as always having been "so nice" (line 686) and that she was the good girl in the family who, unlike her sisters, did not cause any trouble.

In relation to her pupils and their parents she presented herself as fearful and on her guard - she has to beware that they do not "catch her" (line 96) for not knowing enough about her subject. She feels tense and anxious before entering the class room, and the parents' meetings are "of course an entirely different case" (line 44), meaning that they are even worse.

In relation to the headmaster she pictured herself as expecting him to be surprised at her announcement of staying out of work: “because in school I haven’t said anything [about my problems]" (line 118). Then she herself appears to be astonished by how he showed an understanding attitude towards her, evidently not being as astounded by the news as she had expected.

In relation to the health professionals she described herself as opposing, but at the same time accepting, their assessment of her situation. She felt intimidated by the diagnoses: "depression that sounds as such a terrible strong word" (line 141). However, she did not contest the assessments of her condition, and she followed the prescriptions of taking medicine and to seek therapy but in her telling these are pictured as strange and alarming.

In relation to her husband she presented herself in various positions. She mostly referred to him as "the husband", instead of using his first name. He can be called upon when she needs help but his attitude is not told as helpful. He says that she does not need to reveal the real reason for staying out of work but she cannot "pretend anymore" (line 110). Later in the session she tells about her husband's drinking problem and untoward behaviour: "there is this kind of psychological abuse" 
(line 317). She says that "they are there somewhere as a lump all those things" (line 362). Her relation to him appears as blurred - his words and doings affect her in a way which she has difficulties to articulate: "so this is what this man is like (...) can this man act like this" (lines 323324). The relationship is presented as alienated and her attitude as increasingly critical.

This questioning of her relationship with the husband, and of the position she has assumed within it, is also expressed in her telling of her experience of participating in an Al Anon group. She has found it difficult to accept the other women's attitude: “they are married to an alcoholic and still they can somehow live their own lives" (lines 436-437). For her it had felt odd that "somehow you don't let it [the drinking] bother you but still you have there the alcoholic by your side" (lines 449450).

In relation to the therapy the client, by strongly taking the initiative to talk and give meticulous descriptions of her situation and problems, gave the impression of seeking the position of a compliant client. Then, on the other hand, her mode of telling was that of reporting and full of details, creating an image of an outsider perspective, and of her as participating only due to the circumstances. This changed when she started to talk about the marital problems and her relations to her parents and sisters. Interestingly, after having dwelled on these issues for some time, she says: "are these issues relevant here but if I still [say something] about myself ... " (lines 663-664); as if asking whether she is permitted to take ownership of her own experience and perspective.

\section{Causal Attributions}

In the initial problem formulation the client's causal attributions were mostly external and situational: "all the spring I was anxious about returning to work" (lines 35); "even just being in front of others, before the class only [is difficult] for me" (line 42); "I start to have also these kind of physical symptoms” (line 69); “There was not a single day that I wouldn't have thought about returning to work" (lines 70-71). Attributions were also given to essentialized characteristics of herself: "I am too conscientious" (line 76); "I am sensitive, I observe myself” (line 155). 
In later accounts of her life situations the attributions became more internal and personal: "such a terrible kind of checking, I know" (lines 94-95); "I started to have this feeling am I now really crazy" (line 197); "I have somehow noticed [this] am I that kind of nice girl all the time" (lines 665666). Thus, in such attributions, the reasons for her troubles were not placed in outer or inner circumstances but in her own ways of taking stances ("checking", "having a feeling", "having noticed"), thus rendering her a more agentic position in relation to the problems.

\section{Intentionality}

The client mainly presented her intentions as non-agentic, in the sense that they were mostly adapted to her perceived expectations of others towards her. In work her intention had been to prepare her classes conscientiously and make sure that the pupils do not "catch" her for not knowing something. She struggled not to show her insecurity to her colleagues and this changed only when the anxiety and the feeling of burn out got too strong: "I thought that I can't pretend anymore" (lines 110-111). Still, she pictured herself as overtly responsible: "The doctor suggested a longer sick leave but I said I cannot be away even two weeks" (lines 123-124). In her account the main intention presented is one of enduring difficulties and avoiding causing troubles to others.

Also in close relationships she presented her intentions as have been, throughout her history, to comply with others' wishes, to endure misbehaviours, and take responsibility for conflicts. In relation to her parents her intention was told as having been to be "a good girl" who does not make troubles: "I would never have dared to do like that [as her sister did] ... I still think about what mum and dad would say about this or that" (lines 682-684). She told how she "apologized" for taking this kind of husband who is not well educated and is ill-behaved when drunk: "I used to have these feelings of guilt ... that I know that he is not the ideal son-in-law" (lines 707-711).

When accounting for her relation to her husband and his abusive behaviour the client presented her intentions with some self-reflection. Her aim, which she now started to question, had been to tolerate and endure all: "I take in everything and sometimes it feels that I am even guilty for his 
drinking" (line 260). She had been trying to control her husband's drinking, and even keeping records of it, but now she doubtfully asked "if there is anything that I can do about it" (line 422).

In the client's account intentions were closely connected to relations. Her main intention in regards to others appeared as having been to hide herself, as showing herself as not having intentions, i.e. demands or requests, of her own. That intention then placed her outside mutual intersubjective connections in her relational field and positioned her as less agentic.

\section{Historicity}

In the earlier part of the session, when the client was describing her symptoms and problems, history was present in the form of detailed descriptions of events just following each other. Historytelling in the form of such temporal sequencing of events - creating a chronology - pictured her as an external observer of what happened to her: "already last year I started to terribly [worry] somehow that how am I going to cope" (lines 38-39). Thus, her problem accounts were mostly ahistorical in the sense that they were mainly reports of her affective and bodily reactions, the doings of herself and others, and other events; not including her own subjective point of view. She does not give any interpretations to her reactions, nor does she evaluate their possible reasons or consequences.

Later in the session she articulated detailed biographical stories of her relationships in her family of origin and in her present family. She repeatedly presented her own position as a "good girl" (conscientious, forgiving, asking forgiveness, obeying) in her important relationships, and as a reactive - not active - person being influenced by circumstances and the decisions of others.

Historicity in the sense of temporal dialectics between the experienced past and the present moment of telling was scarce in her accounts. She adopted an interpreting subject position very cautiously. Talking about her family of origin she stated: "I have the sense that I have always somehow been told that I am so, that I don’t demand anything, I am so nice ...” (lines 685-686). After having told many stories about her subjugated position in the couple relationship she, 
responding to a question by the therapist, pondered: "Somehow it often feels like is he using to his advantage this that I am so terribly forgiving ...” (lines 691-692). Thus, she did make an effort to relate patterns and positionings to each other, but her interpretations of the meaning of the past for her present situation were uncertain and tentative.

\section{Reflexivity}

In the client's accounts the presence of evaluative and reflective talk was scarce. When occurring, reflexivity contributed in various degrees to the display of agency in the other aspects. Connected to relationality reflexivity increased during the session. Talking about her husband she elaborated her reflections starting with a question (“Is he like this?"); then an evaluative statement of facts ("He did things against my will.") ; then questions implying related positionings ("Am I so unimportant for him?”, “Is he using my forgiveness?”). This last question related her forgiving attitude to his abuse, thus displaying a mutual, intersubjective positioning and a more agentic stance.

Talking about her family of origin she reflected on her position as a "good girl" by pondering on the expectations put on her: "There were not necessarily any kind of direct messages that were given me [but] a little bit like that that I somehow felt that something is expected of me" (lines 673675); and by comparing her position to that of her two sisters who did things that "she would never have dared to do" (lines 681-682).

In the client's attributions of reasons for her work-related problems, reflexivity was hardly present. She, on one hand, described her anxiety and physical reactions, loss of appetite, and her constant crying and thinking about her work, as self-evident things just happening to her. On the other hand, she blamed her own attitudes (e.g. "I'm too conscientious") for her troubles. This did not appear as a reflection, though, rather as still another way of naming causes outside her power of impact. 
Reflexivity was missing from the client's presentations of intentionality. Her intentions were hardly outspoken and her main intention appeared to be to hide herself from others, and even from herself. That intention could not afford a reflective stance towards the purposes of her actions. In her narratives of the past, however, increasing reflexivity was present and contributed to the tentative construction of a historical, agentive position were the past started to be related to the present experience.

\section{Discussion}

We performed a theory-guided qualitative content analysis on accounts of problems and lifesituations given by a female client in her first psychotherapy session. The aim was to try out how a model of discursive agency construction - The Five Aspect Model - could embrace the different ways in which the client adopted the double position of presenting herself as having a lost sense of agency, and a willingness to address her problems in conversational therapy. This model of agentic versus non-agentic display had been developed in an earlier study on (non)agency constructions of clients in semi-mandatory counselling for repeated drunk driving offenders (Seilonen \& Wahlström, 2016). The present study can be seen as an attempt to assess the transferability (Lincoln \& Guba, 1985) of that model to a different kind of case, i.e. one in which the client enters psychotherapy voluntarily.

The analysis showed that the model was able to specify how the client's account constructed her positions in regard to her problems, her relations to others, herself, and the therapy in various ways as more or less agentic. The quality of non-agentic positioning varied between the different aspects suggested by the model, and with respect to topics and/or contexts:

Relationality: When talking about her presenting problem (social anxiety) and action to be taken in respect to it, she pictured herself as depending on others. In regard to her close relationships she presented herself as a person who accommodates to the image she has of what 
others expect from her. This non-agentic self-positioning lessened, when in her account she started to adopt a budding reflective stance, and hence a potential differentiation within self/other related agency ascriptions.

Causal attribution: She moved from external and situational attributions to self-related ones. The latter took, though, mainly the form of giving essentialized characteristics as causes, and hence did not contribute to the construction of agentic formulations

Intentionality: She presented herself as non-intentional, i.e. as not wanting to impact her social surroundings. Her ultimate intention appeared to be to endure her troubles and hide her "true self" from others, and even from herself.

Historicity: She started by giving very detailed, but not reflected, accounts of events in her life but adopted gradually, although with caution, a more reflecting and interpreting stance in her narration of past events in her life.

Reflexivity: Reflection, as a quality of accounting, increased in the presentations of relationality and historicity, but scarcely in the presentations of causal attributions or intentionality.

In our earlier case study on three clients in semi-mandatory counselling for repeated drunk driving (Seilonen \& Wahlström, 2016), we could, using the Five Aspects Model, distinguish between different discursive strategies used by the clients for constructing non-agency, and for actually evading a position as a credible client. In the present study we could notice how the client, over the course of the first session, moved from a pointedly non-agentic self-positioning towards an emerging reflexivity in the account. In this respect she clearly presented herself as a credible psychotherapy client.

The comparison between the "non-willing" clients of the former study and the "willing" one in the present study is multi-faceted, though. A reactive and adoptive positioning to others was observed also in one of the earlier cases, whose agency display was labelled as "unconcerned". Still, the functions of such a positioning appeared to be different - in the drunk-driving case that of 
getting over and managing troubles, in the social anxiety case that of avoiding causing any trouble. The positioning of herself as helpless could be understood as an attempt to influence her social surroundings by assuming a non-agentic position. In the drunk-driving case the adoptive position to others seemed to be situationally useful for the client.

In respect to causal attributions, two of the drunk-driving cases exhibited only situational, external causes for their actions, whereas one, labelled as "akratic" (i.e. acting against his own will) in his agency display, referred to his inner states as causes for action. The present case seems to obtain a place in between. Her account moved a step towards internal attribution, without actually including such presentations.

The three cases of drunk-driving clients differed clearly from each other in respect to how intentionality was presented in their accounts. Intentions were actively warded off (the so called “disowned" agency display), ambivalent or irrelevant ("unconcerned" agency), or reflected ("akratic" agency). In the social anxiety case, interestingly, intentionality appeared as the aspect least in use in the constructing of an agentic display. Non-intentionality was not, though, presented bluntly as in the case of "disowned" agency, but rather as something self-evident not even in need of consideration.

It appears that reflexivity was the one aspect of agency display in which the client seeking voluntary psychotherapy differed the most from those signed up for semi-voluntary counselling. The clients representing "disowned" and "unconcerned" agency display exhibited no reflexive stance in respect to their actions, while the one representing "akratic" agency did so otherwise, but not so when a moral evaluative position of the self would have been called upon. The present case, again, clearly moved during the course of the session from a non-reflective stance towards evaluative and pondering statements on her relational positions.

Of the three cases in semi-mandatory counselling, only one - the "akratic" one - took up an actual client-position by presenting himself as a person with subjectively experienced problems. 
The self-positioning within the therapy-context of the self-referred and voluntary client of the present study clearly changed during the session. In the earlier parts of the session she presented herself as being more or less forced by circumstances to seek help (a stance underlined by the fact that her father was the original caller). Later she, in a rather inconspicuous way, assumed the position of a client with an active interest in exploring her troubles within the contexts of her present relationships and personal history.

We conclude that the Five Aspects Model of agency display - integrating viewpoints from epistemology, cognitive psychology, psychoanalysis, constructionism, and contemporary conceptualizations of relationality - contributed to a detailed description of how the clientparticipant in this case study successfully fulfilled the institutional task of a prospective psychotherapy client. It should be noted that the analysis in this study was "closed" in the sense that we did not look for possible new categories that might have emerged from an open analysis. It is also obvious that due to the very limited number of cases analysed so far, the Five Aspects Model is only tentative. We need further case studies to determine to what degree the model saturates the variety of agentic versus non-agentic display in problem formulations.

We also want to underline that this discursive work was mainly performed by the client, and to suggest the importance of further studies on how clients contribute to the construction of psychotherapeutic encounters as curative contexts. We conclude that qualitative process research could benefit from considering loss of agency as one crucial object of psychotherapy and the ongoing discursive formulations and re-formulations of the client's more or less agentic positions as central to the process of therapy. 


\section{References}

Avdi, E. (2005). Negotiating a pathological identity in the clinical dialogue: Discourse analysis of a family therapy. Psychology and Psychotherapy: Theory, Research and Practice,78, 493511.

Avdi, E. (2012). Exploring the contribution of subject positioning to studying therapy as a dialogical enterprise. International Journal for Dialogical Science, 6, 61-79. Avdi, E, Lerou, V. \& Seikkula, J. (2015). Dialogical features, therapist responsiveness, and agency in a therapy for psychosis. Journal of Constructivist Psychology, 28, 329-341.

Bamberg, M. (2009). Identity and narration. In P. Huehn, J. Pier, W. Schmid \& J. Schoenert (Eds.), Handbook of narratology (pp. 132-143). Berlin: Walter de Gruyter.

Bruner, J. (1990). Acts of meaning. Cambridge, MA: Harvard UP.

Dimaggio, G. (2011). Impoverished self-narrative and impaired self-reflection as targets for the psychotherapy of personality disorders. Journal of Contemporary Psychotherapy, 41, 165174.

Drewery, W. (2005). Why we should watch what we say. Position calls, everyday speech and the production of relational subjectivity. Theory \& Psychology, 15, 305-324.

Georgaca, E. (2001). Voices of the self in psychotherapy: A qualitative analysis. British Journal of Medical Psychology, 74, 223-236.

Gillespie, A. (2012). Position exchange: The social development of agency. New Ideas in Psychology, 30, 32-46.

Harré, R. (1995). Agentive discourse. In R. Harré \& P. Stearns (Eds.), Discursive psychology in practice (pp. 120-136). London, UK: Sage Publications Ltd.

Jenkins, A.H. (2001). Individuality in cultural context: The case for psychological agency. Theory \& Psychology, 11, 347-362. 
Karatza, H., \& Avdi, E. (2011). Shifts in subjectivity during the therapy for psychosis. Psychology and Psychotherapy: Theory, Research, and Practice, 84, 214-229.

Kupferberg, I., \& Green, D. (2005). Troubled talk: Metaphorical negotiation in problem discourse. Berlin: Mouton de Gruyter.

Kögler, H-H. (2010). Recognition and the resurgence of intentional agency. Inquiry, 53, 450-469.

Kögler, H-H. (2012). Agency and the Other: On the intersubjective roots of self-identity. New Ideas in Psychology 30, 47-64.

Levitt, H., Pomerville, A., \& Surace, F. (2016) A qualitative meta-analysis examining clients' experiences of psychotherapy: A new agenda. Psychological Bulletin, 142, 801-830.

Lincoln, Y.S., \& Guba, E.G (1985). Naturalistic inquiry. Beverly Hills, CA: Sage.

Mackrill, T. (2009). Constructing client agency in psychotherapy research. Journal of Humanistic Psychology, 49, 193-206.

Markova, I. (2003). Constitution of the self: Intersubjectivity and dialogicality. Culture and Psychology, 9, 249-259.

Mayring, Ph. (2014). Qualitative content analysis: theoretical foundation, basic procedures and software solution. Klagenfurt. Retrieved from http://nbn-resolving.de/urn:nbn:de:0168ssoar-395173.

Ogden, T.H. (1986). The matrix of the mind. Object relations and the psychoanalytic dialogue. Northvale, NJ: Jason Aronson Inc.

Pope, R. (1998). The English studies book. London, UK: Routledge.

Rennie, D.L. (2010). Humanistic psychology at York University: Retrospective: Focus on clients` experiencing in psychotherapy: Emphasis of radical reflexivity. The Humanistic Psychologist, 38, 40-56. 
Seilonen, M-L., \& Wahlström, J. (2016). Constructions of agency in accounts of drunk driving at the outset of semi-mandatory counseling. Journal of Constructivist Psychology, 29, 248268.

Wahlström, J. (2006). The narrative metaphor and the quest for integration in psychotherapy. In E.O`Leary \& M. Murphy (Eds.), New approaches to integration in psychotherapy (pp. 3849). London, UK: Routledge. 